\title{
Busca autônoma por educação permanente e consolidação da identidade profissional critica
}

\author{
Search autonomous for continuous education and consolidation of professional critical \\ identity \\ Nilsen Aparecida Vieira Marcondes* \\ Elisa Maria Andrade Brisola** \\ Edna Maria Querido de Oliveira Chamon ${ }^{* * *}$
}

\begin{abstract}
Resumo:
Refletir acerca da educação permanente como meio de aprimoramento intelectual, na perspectiva da competência profissional e da consolidação da identidade profissional crítica do assistente social, emerge como necessidade no atual contexto histórico, no qual o dinamismo societário caminha apressadamente. Por meio de uma pesquisa qualitativa, utilizando-se da história oral, por meio de entrevista semiestruturada, alcançou-se conhecimento sobre as formas utilizadas pelos profissionais de Serviço Social na busca autônoma por educação permanente. Os resultados do estudo apontam que a totalidade dos entrevistados é unânime em afirmar que a qualificação continuada é de suma importância para a consolidação da identidade profissional crítica, potencialização das competências e das atribuições privativas dos assistentes sociais, contribuindo, assim, para a efetivação do Projeto Ético-Político da profissão, além de portar a tendência de se repercutir positivamente no alcance da qualidade dos serviços prestados.
\end{abstract}

Palavras-chave: Educação permanente; Identidade profissional; Serviço Social.

\begin{abstract}
:
Reflect on the continuing education, as enabler of intellectual improvement, from the perspective of professional competence and the consolidation of professional identity of critical social worker, emerges as a necessity in the current historical context, in which the dynamism corporate walks hurriedly. Through a qualitative study using oral history, through semi-structured interview was achieved knowledge about the ways used by the Social Service professionals in search unattended for continuing education. The study results show that all the respondents are unanimous in stating that the continued qualification is of paramount importance to the consolidation of professional identity critical enhancement of skills and responsibilities of private social workers, thus contributing to the realization of the Project ethical-Political profession, besides possessing a tendency to impact positively on the range of quality services.
\end{abstract}

Key words: Continuous education; Professional identity; Social Work.

\footnotetext{
* Assistente Social. Mestre em Desenvolvimento Humano. E-mail: nilsenmarcondes@gmail.com

** Assistente Social, Doutora em Serviço Social pela PUC-SP. Docente d da Universidade de Taubaté/SP. E-mail: elisabrisola@uol.com.br

*** Pedagoga. Doutora em Psicologia Social pela Universidade de Toulouse II, França. Professora da Universidade de Taubaté. E-mail: edna.chamon@gmail.com
} 


\section{Introdução}

Assumindo como ponto de partida as narrativas dos assistentes sociais pesquisados, procura-se, neste artigo, apresentar as motivações que levaram esses profissionais a buscar, por iniciativa própria, a educação permanente, entendendo essa busca como contributo à consolidação de sua identidade profissional crítica, potencialização das competências e das atribuições privativas dos assistentes sociais, colaborando, assim, para a efetivação do Projeto Ético-Político da profissão, além de portar a tendência de se repercutir positivamente no alcance da qualidade dos serviços prestados.

Defende-se também a relevância das normatizações que focalizam e concretizam este aspecto da vida profissional, qual seja, a educação permanente, atribuindo-lhe visibilidade e importância como, por exemplo, a Norma Operacional Básica de Recursos Humanos do Sistema Único da Assistência Social (NOB-RH/SUAS) e a Política de Educação Permanente elaborada pelo Conselho Federal de Serviço Social (CFESS) em conjunto com os Conselhos Regionais de Serviço Social (CRESS).

Tal defesa caminha na direção de uma abordagem que foge ao viés positivista, o qual concebe a educação como a base de tudo e como realidade que transforma a vida das pessoas. Ao contrário, sustenta-se que educação não transforma, mas sim possibilita transformação. Na contramão da perspectiva teórico-conceitual positivista e hegemônica, sustenta-se uma educação como práxis, ou seja, como grande meio de transformação, como realidade com potencial para gerar o movimento da consciência, mas também da ação. Diante do vasto horizonte que se coloca para a área do Serviço Social, é essencial ter presente a forte vinculação entre competências e atribuições versus exercício profissional e educação permanente, afinal, o cumprimento do complexo rol de responsabilidades do assistente social somente será efetivado a contento mediante a busca contínua, e muitas vezes autônoma, por educação permanente, entendendo-a como o pano de fundo, como alicerce, como base sobre a qual se constroem e se consolidam as competências, atribuições, ou seja, o exercício profissional.

Entende-se a importância da educação, em especial da educação permanente, porém acredita-se que somente a educação permanente não seja suficiente para promover transformações no interior da profissão com consequentes reflexos na consolidação da identidade profissional crítica, principalmente se tal educação permanecer somente no 
plano teórico. É preciso que exista articulação entre movimento da consciência e da ação como condição necessária ao estabelecimento do desenvolvimento que se intenciona alcançar no interior da categoria profissional mediante a educação permanente.

A educação permanente afirma a centralidade de uma intervenção profissional pautada num movimento contínuo de reflexão crítica e de ação. Compreende-se esse movimento como mediação necessária no interior do Serviço Social, por isso considera-se a importância da reflexão sobre essa temática, dando-Ihe a conotação devida.

É importante compreender que a educação permanente tem como direção o aperfeiçoamento não apenas da dimensão epistêmica, mas também das relações sociais. A essa compreensão acrescenta-se o reconhecimento de que, enquanto processo, cujas raízes encontram-se na certeza de que o ser social possui como característica a inconclusão, a educação permanente apresenta-se, conforme Freire (1994, p. 42), como “[...] um que-fazer permanente. Permanente, na razão da inconclusão dos homens e do devenir da realidade".

De acordo com o Conselho Federal de Serviço Social (2012, p. 27):

A educação permanente deve contemplar também a dimensão do aprimoramento teórico-metodológico, técnico-operativo e ético-político, no sentido de potencializar uma análise da realidade social de forma a qualificar a intervenção profissional do/a assistente social.

Portanto, a intensificação do debate teórico acerca dessa questão significa caminhar ao encontro dos desafios que exigem do profissional, segundo Gatti e Barreto (2009, p. 200), uma “[...] atualização e aprofundamento de conhecimentos como requisito natural do trabalho em face do avanço nos conhecimentos, as mudanças no campo das tecnologias, os rearranjos nos processos produtivos e suas repercussões sociais".

Essa assertiva

[...] indica e reforça a direção da educação permanente da formação em Serviço Social, que associa elementos técnico-operativos da prática profissional às dimensões teórico-metodológica e ético-política como unidades indissociáveis, que se estendem da graduação à pós-graduação (CONSELHO FEDERAL DE SERVIÇO SOCIAL, 2012, p. 19-20).

A educação permanente, na sua dimensão teleológica, ou seja, enquanto realidade que busca a finalidade de sua própria aplicação, relacionando-se a si mesma com sua causa final, condensa realidades amplas, na medida em que se considera que a educação 
permanente, além de trazer em seu bojo a possibilidade de ampliação do conhecimento, desdobra-se também na socialização desse conhecimento adquirido, o que potencializa a capacidade de edificar novas formas de compreender os contextos (SPOSATI, 2007) e, assim, produzir conhecimentos constituídos por subsídios teórico-metodológicos que estejam de acordo com as exigências da sociedade (BOURGUIGNON, 2007).

Em concordância com Bourguignon (2007), para os profissionais de Serviço Social que buscam se imbuir de um caráter crítico em suas ações, bem como assumir uma postura propositiva no contexto nacional, faz-se preeminente a compreensão de que o processo de produção do conhecimento, ou ainda a aquisição dele, constitui-se de uma mola propulsora para a transformação do cenário social.

\section{Metodologia}

Por meio de uma pesquisa qualitativa, utilizando-se da história oral, e de entrevista semiestruturada, alcançou-se conhecimento sobre as formas utilizadas pelos profissionais de Serviço Social na busca autônoma por educação permanente. Os procedimentos analíticos aqui expostos para a interpretação das narrativas pautam-se na Triangulação.

O emprego da Triangulação para a análise das informações coletadas prevê dois momentos distintos, os quais se articulam dialeticamente, favorecendo uma percepção de totalidade acerca do objeto de estudo e da unidade entre os aspectos teóricos e empíricos, sendo esta articulação a responsável por imprimir o caráter de cientificidade ao estudo.

O primeiro momento diz respeito à preparação dos dados empíricos coletados, mediante diversos procedimentos a serem adotados. Esses procedimentos são representados por etapas sumárias que visam à organização e ao tratamento das narrativas. Para Minayo (2010), o segundo momento se refere à análise propriamente dita, que implica a necessidade de se refletir sobre: primeiro, a percepção que os sujeitos constroem sobre determinada realidade; segundo, os processos que atravessam as relações estabelecidas no interior dessa estrutura, e, para isso, a recorrência aos autores que se debruçam sobre tais processos e a temática trabalhada na pesquisa são imprescindíveis; terceiro, as estruturas que permeiam a vida em sociedade.

Os sujeitos deste estudo foram seis assistentes sociais assim distribuídos: um num município de pequeno porte e atuante numa unidade pública estatal, qual seja, o Centro 
de Referência de Assistência Social (CRAS) da cidade; um num município de médio porte, exercendo suas atividades numa organização social do segmento Pessoa com Deficiência; e quatro num município de grande porte, sendo dois profissionais representantes de dois CRAS da cidade e dois de organizações sociais respectivamente do segmento Família e Criança e Adolescente. No total, a representatividade abarcou três municípios com densidade populacional diferenciada, três representantes de Organização Governamental e três representantes de Organizações Não Governamentais (ONGs) atuantes na área da Família, Criança e Adolescente e Pessoa com Deficiência.

Os entrevistados participantes desta pesquisa consentiram com a realização do estudo, os quais tiveram esclarecimentos sobre os objetivos e assinaram o Termo de Consentimento Livre e Esclarecido. A pesquisa foi encaminhada ao comitê de ética da Universidade localizada na área de abrangência dos municípios pesquisados, tendo sido aprovada sob o Protocolo n. 379/11.

Portanto, cada narrativa, recolhida e organizada, traz consigo as formas utilizadas pelos profissionais de Serviço Social na busca autônoma na educação permanente e no quanto existe de imbricamento dessa realidade com a consolidação de uma identidade profissional crítica. Nesse sentido, buscar-se-á, mediante o enfoque analítico da objetividade e da subjetividade, refletir sobre o assunto.

\section{Resultados e discussão:}

\section{Refletindo sobre Educação Permanente}

Apesar de o poder público ter responsabilidades no oferecimento de oportunidades que possibilitem a educação permanente dos profissionais envolvidos com as diversas políticas públicas, isso não desobriga o assistente social de buscá-la. No tocante a essa questão, para aferir essa busca autônoma por educação permanente, apresenta-se a seguir algumas narrativas dos profissionais entrevistados. Partindo da análise destas indicações empíricas, percebe-se o quanto a articulação de tais falas aponta para a relevância da capacitação no cotidiano de trabalho.

Ao oferecerem suas contribuições acerca da busca autônoma por educação permanente e a consolidação de uma identidade profissional, os assistentes sociais entrevistados não contraditam aquilo que é propugnado pelos diversos autores citados na 
construção deste artigo, como pode se verificar na fala do entrevistado 1: "Para minha formação continuada, procuro participar de cursos e grupos de estudos por conta própria, assim iniciei minha pós-graduação, financiada com recursos próprios" (E1). O entrevistado 2 reforça essa assertiva: "Com um ano de formação e atuação, senti a necessidade de uma especialização, e me matriculei no curso de pós-graduação" (E2). O entrevistado 3 complementa: "A gente precisa mesmo estar se capacitando sempre. Eu sinto uma necessidade muito grande em me atualizar" (E3). Na sequência, o entrevistado 6 demonstra em sua narrativa que, mesmo diante de alguns obstáculos, o desejo por qualificar-se permanece como meta a ser alcançada:

Faz-me muita falta os cursos de capacitação. A gente se reúne aqui no CRAS semanalmente para estudos e a gente busca também informações no site do Ministério de Desenvolvimento Social, para estar mais seguro até hoje não foi possível fazer uma pós-graduação como eu gostaria, mas tenho participado de seminários, palestras. A gente está sempre interessada em crescer e aprender aqui no CRAS, a gente sempre se obriga a buscar mais e mais informações, $e$ autonomamente mesmo, e de onde a gente puder buscar informações mais $e$ mais, isso é uma coisa que a gente faz com grande prazer aqui no CRAS (E6).

Nas narrativas dos assistentes sociais 1, 2 e 6, verifica-se que a questão da pósgraduação, seja ela stricto, seja lato sensu, que ganha destaque em suas falas. Ao se reportarem a esta realidade, deixam transparecer isso, principalmente o entrevistado 1 , ao afirmar que, logo após "um ano de formação e atuação, senti a necessidade". A fala demonstra o quanto o exercício profissional cotidiano exige educação permanente sob pena de o profissional sofrer retração em sua prática concreta ou mesmo encontrar-se impossibilitado de responder competentemente às demandas advindas da realidade social. Verifica-se, portanto, o quanto o encorajamento e o comportamento de busca contínua que se assume na construção e no fortalecimento da identidade profissional crítica nascem da inquietação que acompanha os profissionais desde a graduação.

A Pós-Graduação do Serviço Social, por intermédio de seus núcleos de pesquisa estáveis, legítimos e reconhecidos, configura-se como a mais importante sustentação das investigações e da produção científica da área. A característica marcante dos Programas de Pós-Graduação em Serviço Social no Brasil está no ensino. Esses Programas possuem uma relevante função no que se refere à formação de profissionais para a docência tanto para o país quanto para outras nações latino-americanas, como a Argentina, o Uruguai, o Chile, 
a Costa Rica, a Colômbia e a Venezuela, além do continente europeu, particularmente Portugal (GUERRA, 2011).

Guerra (2011) afirma que, apesar de a Pós-Graduação em Serviço Social estar direcionada à docência, ganha corpo também uma formação voltada à consolidação de uma categoria profissional representativa de uma tendência crítica, a qual se encontra imersa na formulação e implementação de políticas sociais, nas atividades desenvolvidas pelos conselhos de direitos, pelas organizações governamentais e não governamentais e, ainda, mesmo que numa representatividade menor, nas intervenções relacionadas aos movimentos sociais. Para essa autora:

Os Programas [de Pós-Graduação em Serviço Social] encontram-se bem estruturados com disciplinas apresentando conteúdo e bibliografia atuais e em conexão com as áreas de concentração e linhas de pesquisa. Ressalta-se que a procura pelos nossos Programas extrapola a área de Serviço Social: muito dos candidatos que os procuram são de áreas afins e estão interessados num debate crítico que se faz em torno do capitalismo contemporâneo e suas formas de enfrentar a chamada questão social (GUERRA, 2011, p. 146).

lamamoto (2011) lembra também que, no âmbito da graduação e da intervenção técnica cotidiana, a produção do conhecimento tem se feito presente por meio do incentivo dado aos graduandos à realização de atividades de pesquisa e à valorização de ações investigativas realizadas por profissionais em seu próprio ambiente sócio ocupacional.

Guerra (2011), ao analisar os principais temas de interesse para pesquisas, aponta para uma especialização profissional com acentuada tendência para retratar aspectos históricos que envolvem os contextos das transformações as quais são decorrentes dos processos relacionais que se estabelecem entre o Estado brasileiro e a sociedade, num período marcado pela forte presença das relações internacionais. Desse contexto, emergem polêmicas temáticas que demarcam um denso debate do Serviço Social com o acentuado deslocamento das realidades presentes no interior da sociedade.

Além da pós-graduação em franca expansão, não obstante esse fato ser decorrência das demandas do capital, mas também motivado e alimentado pelo crescente interesse e pela busca por parte da categoria profissional, outras modalidades de educação permanente também são almejadas pelos profissionais ávidos por reciclar seus 
conhecimentos obtidos na graduação. A narrativa da entrevistada 3, apresentada na sequência, reflete bem esse desejo:

Eu acredito que a gente está sempre precisando renovar as nossas informações. Então quando possivel eu busco o conhecimento através dos eventos municipais, dos encontros, palestras, simpósios, reuniões ampliadas, conferências realizadas pelos Conselhos Municipais daqui da cidade e até dos próprios palestrantes que a gente convida para a nossa formação interna aqui [na organização social] (E3).

Numa outra direção analítica, ou seja, em relação ao acesso à educação permanente, e não por meio da pós-graduação, defende-se que a participação regular em eventos, encontros temáticos, palestras, simpósios, seminários, reuniões ampliadas, conferências, capacitações de curta duração, entre outras correlatas, também se apresenta inquestionável quanto à sua importância, na medida em que tais modalidades igualmente podem contribuir de forma muito eficaz para o preenchimento das lacunas deixadas pela fase pretérita da vida do profissional.

Essa afirmação, validada pela narrativa supracitada, permite considerar que ações na direção da educação permanente, desde que não se configurem como intermitentes, favorecem a desconstrução de um possível pragmatismo que, segundo lamamoto (2011), pode dominar a intervenção cotidiana do assistente social, obstando a tomada de consciência acerca de seu compromisso com a defesa de processos democráticos que favoreçam a emancipação humana, a defesa dos direitos e as conquistas da classe trabalhadora, acumulados durante um extenso percurso histórico de batalhas.

Nessa mesma linha de reflexão, qual seja, sobre a importância da participação regular em eventos, capacitações de curta duração, enfim, é necessário trazer à análise os esforços de assistentes sociais que atuam como professores universitários, no sentido de promover e de manter espaços de educação permanente por meio de projetos de extensão. As universidades locais têm contribuído consideravelmente nesse aspecto, mediante a iniciativa de seu corpo docente, em atenção ao princípio de indissociabilidade entre ensino, pesquisa e extensão, conforme proposto na Constituição Federal de 1988, em seu artigo 207ㅇ (BRASIL, 1988).

Pelo eixo da extensão, ou seja, pela relação entre a universidade e a comunidade, vários projetos de educação permanente voltados aos profissionais de Serviço Social têm 
sido efetivados. Muitos dos profissionais entrevistados, inclusive a própria pesquisadora, autora deste artigo, participam dessas capacitações oferecidas pelas universidades.

O eixo da extensão, considerado como um dos três pilares da universidade, ao lado do ensino e da pesquisa, além de cumprir um papel hermenêutico diante das ansiedades e necessidades dos assistentes sociais já graduados e envolvidos com a dimensão técnicooperativa do trabalho, possibilita também a reciclagem de suas capacidades teóricometodológicas e ético-políticas.

Essa relação que se estabelece, entre a universidade e a comunidade dos assistentes sociais em pleno exercício profissional, permite uma saudável troca de saberes, na medida em que os assistentes sociais levam seus conhecimentos respaldados pela experiência concreta do seu cotidiano aos docentes, os quais, por sua vez, compartilham seus conhecimentos científicos, promovendo um aprendizado bilateral.

A socialização e a democratização do conhecimento acadêmico, fruto do desenvolvimento de pesquisas realizadas pelos docentes, permitem que o profissional envolvido somente com a prática interventiva tenha acesso a conteúdos que facilitarão seu trabalho de mediação entre a teoria e a prática, além de proporcionar espaços para a reflexão sobre sua a atuação e o fortalecimento das interações entre profissionais de diferentes municípios e espaços sócio ocupacionais distintos, o que, inevitavelmente, contribuirá para o alcance de maior qualidade na prestação de serviços sociais.

No interior do Estado de São Paulo, determinada Universidade destaca-se na efetivação de projetos voltados aos trabalhadores que compõem o Sistema Único da Assistência Social (SUAS). No momento, quatro são os projetos contemplados na extensão universitária. O primeiro deles, voltado à capacitação de conselheiros, objetiva estimular o protagonismo, sobretudo dos membros da sociedade civil e dos usuários da política da assistência social. O segundo tenciona conhecer o trabalho profissional do assistente social no âmbito do SUAS, nos municípios localizados ao redor da referida universidade, tendo em conta a expansão desses profissionais no contexto da crise do capital. Nesse projeto, destaca-se a identificação das práticas, dos saberes, dos fundamentos teóricometodológicos, técnico-operativos e ético-políticos, e das possíveis lacunas ou deficiências referentes à formação profissional e a seus rebatimentos na prestação de serviços sócio assistenciais. O terceiro projeto visa levantar as múltiplas demandas formativas da 
sociedade, na região geográfica onde se situa a Universidade em destaque, levando em consideração o quadro de transformações políticas, econômicas e socioculturais da contemporaneidade, e analisar as políticas sociais dirigidas para o atendimento de tais demandas. O quarto projeto objetiva avaliar a implementação do SUAS na mesorregião geográfica objeto territorial deste estudo. A equipe envolvida nesse projeto busca, por intermédio de suas ações, compreender as diversas dimensões da implementação do SUAS, bem como captar sua processualidade.

\title{
Consolidação da Identidade Profissional
}

Conforme expressa Severino (2011, p. 11): “Poucas áreas das ciências humanas têm revelado tanta inquietação teórica como o Serviço Social. De uma perspectiva filosófica, este esforço para se repensar pelas raízes é muito significativo". Justifica-se a afirmação do autor em decorrência de a história do Serviço Social demonstrar suas profundas raízes com o projeto político ideológico da classe dominante emergente, tendo sido pensado e criado como uma estratégia de intervenção, objetivando evitar confrontos diretos com a classe trabalhadora.

Diante dos fatos, compreende-se que o consequente desenvolvimento da identidade profissional e da consciência social dos assistentes sociais esteve, desde os primórdios, fortemente imbricado pela ideologia dominante: “Essa aliança de berço cria, sem dúvida, uma complicada situação para o Serviço Social quando se propõe a questionar o sentido de sua intervenção na sociedade" (SEVERINO, 2011, p. 11).

Para Martinelli (2011, p. 66-67):

\begin{abstract}
A origem do Serviço Social como profissão tem, pois, a marca profunda do capitalismo e do conjunto de variáveis que a ele estão subjacentes - alienação, contradição, antagonismo. As condições peculiares que determinam seu surgimento como fenômeno histórico, social e como atividade profissional marcaram o Serviço Social como uma criação típica do capitalismo, por ele engendrada, desenvolvida e colocada permanentemente a seu serviço, como uma importante estratégia de controle social, uma ilusão necessária para, juntamente com outras ilusões por ele criadas, garantir-lhe a efetividade e a permanência histórica. O Serviço Social já surge, portanto, no cenário histórico com uma identidade atribuída.
\end{abstract}

A identidade desse profissional, portanto, foi atribuída pela burguesia, e não construída pelos profissionais. Essa atribuição ocorreu por meio de um processo que 
começou pelo seu nascimento e que foi evoluindo ao longo da história. A burguesia precisava consolidar seu poder e, para isso, uma das estratégias utilizadas foi a institucionalização da profissão com sua respectiva atribuição e competência no interior da sociedade.

De acordo com Martinelli (2011, p. 67):

Transitando contraditoriamente entre as demandas do capital e trabalho, e operando sempre com a identidade que lhe fora atribuída pelo capitalismo, o Serviço Social teve roubadas as possibilidades de construir formas peculiares e autênticas de prática social, expressando-se sempre como um modo de aparecer típico do capitalismo, em sua fase industrial.

Assim, era preciso negar essa identidade atribuída, sendo justamente por isso que se fala tanto dentro do contexto do Serviço Social em inquietações teóricas e construção de uma identidade profissional crítica. Segundo Martinelli (2011, p. 35): “Como categoria histórica, a identidade se constrói no movimento da história, ao longo da caminhada da própria classe, que ao produzir a sua existência, a sua vida material, produz a própria história humana". Para essa autora:

A prolongada convivência com as práticas conservadoras e as alianças historicamente construídas com a burguesia acabou por naturalizar a prática do Serviço Social, como uma prática burguesa, sempre subordinada à burguesia ou por ela determinada. O fato de ter operado durante anos seguidos com uma identidade atribuída pelo capitalismo, sem um projeto profissional próprio e específico, marcou historicamente o Serviço Social (MARTINELLI, 2011, p. 139).

Segundo a autora supracitada a construção e a consolidação de uma identidade profissional crítica foi um processo de longa duração. O Serviço Social, posteriormente à atribuição de sua identidade, buscou romper com suas origens burguesas, criticando-a. Gradativamente, a profissão foi recriando sua história no sentido de construir ações interventivas inovadoras que possibilitaram a articulação com as forças sociais que já se encontravam engajadas na luta pela instauração de novos tempos e uma nova sociedade. Essa autora reforça que:

À medida, porém, que os assistentes sociais conseguiram libertar-se dos tentáculos da alienação, iniciou-se uma verdadeira odisseia, ao longo da qual negavam aquilo que tomaram historicamente por válido e real, superando a certeza sensível e a representação imediata. Tornando-se críticos de sua prática e da identidade à qual estava referenciada, adquiriram condições e refletir, procurando desvendar as tramas do real, para poder compreendê-lo, conhecendo a sua estrutura, capturando a sua essência. Nesse movimento de busca, que exige oposição, negação, contradição, a identidade atribuída do 
Serviço Social era questionada, revisitada pelos assistentes sociais, revelando suas inconsistências, fragilidades e submissões à lógica instituída pela sociedade de classes (MARTINELLI, 2011, p. 139-140).

A consolidação da identidade profissional surge como necessidade de extrema relevância, porque sua inexistência debilita a consciência social dos profissionais, estabelecendo um caminho alienado, alienante e alienador de intervenção. Tanto a construção quanto a consolidação da identidade profissional precisam ser compreendidas como realidade de caráter político e sócio histórico que se edifica no entrelaçar das relações sociais. Por isso, a identidade profissional precisa ser refletida como categoria flexível e em constante movimento (MARTINELLI, 2011).

Entre os vários fatores que, na atualidade, contribuem para a consolidação dessa identidade profissional, aponta-se para duas realidades as quais, segundo os entrevistados, têm potencial para romper com a paralisia da consciência social e com a prática reprodutora da ideologia capitalista. São elas: a educação permanente e a participação em órgãos representativos da categoria.

\section{Contributos da Educação Permanente à Consolidação da Identidade Profissional}

A educação defendida como permanente se coloca como disseminadora de possibilidades com vistas à consolidação da identidade profissional crítica, na medida em que acompanha o movimento inerente ao contexto sócio histórico no qual a identidade profissional se encontra.

Conforme Martinelli (2011), pensar a consolidação da identidade profissional como algo eminentemente dinâmico, edificando-se constantemente no embate com as contradições presentes na realidade concreta, mediada por determinismos sociais, aponta para a "noção de trajetória", para usar os termos de Bourdieu.

O profissional de Serviço Social transita por diversos espaços geográficos, sócio ocupacionais e políticos devido às configurações do mundo do trabalho. Em decorrência disso, não é casual a fala do entrevistado 2 ao afirmar que: "O assistente social precisa estar em sintonia com o contexto onde ele se encontra, e hoje em dia as mudanças ocorrem com muita frequência, portanto, a formação continuada vem para contribuir sim na atualização de todo e qualquer profissional" (E2). 
Acrescenta-se a esse fato a importância da consolidação de uma identidade profissional que permita ao assistente social tornar-se cada vez mais capacitado para realizar uma profunda análise da relação entre sistema capitalista e políticas públicas para, assim, poder estar "em sintonia com o contexto", conforme defende o entrevistado 2 . Essa necessidade de análise ultrapassa o ambiente imediato no qual o profissional pode estar inserido e representa uma das premissas básicas, capaz de fornecer condições para intervir no enfrentamento das diversas expressões da questão social.

Na Política Nacional de Educação Permanente, a matéria textual inerente à sua operacionalização reforça a importância de se ater à formação e à consolidação da identidade profissional crítica do assistente social, principalmente como forma de impedir ou mesmo minimizar os efeitos da fragmentação e da imediaticidade de conteúdos que estejam destoantes do projeto de formação profissional, os quais podem favorecer a reprodução e o ressurgimento do pensamento conservador no interior da profissão (CONSELHO FEDERAL DE SERVIÇO SOCIAL, 2012).

De outro lado, a ênfase na defesa da educação permanente ocorre, também, porque o investimento na qualificação do assistente social contribui para o fortalecimento do Projeto Ético-Político da profissão. De acordo com Rodrigues (2011, p. 6):

\begin{abstract}
O Projeto Ético-Político do Serviço Social representa um norte na atuação dos assistentes sociais, na perspectiva da construção de uma nova ordem social, sem discriminação de qualquer forma (de gênero, raça, geração, orientação sexual) e exploração, na qual todos tenham realmente acesso aos direitos para satisfação de suas necessidades. Este Projeto Ético-Político teve seu marco simbólico datado de setembro de 1979 a partir do qual o Serviço Social revê sua visão de mundo, de homem e de sociedade por meio do aporte teórico do materialismo dialético de Marx. A construção do Projeto Ético-Político do Serviço Social se inscreve no contexto das lutas políticas mais amplas da sociedade brasileira, nas quais os profissionais do Serviço Social se inserem, como a luta contra a ditadura militar no período de 1964 a 1985 (RODRIGUES, 2011, p. 6).
\end{abstract}

O contexto de lutas políticas de que trata Rodrigues (2011) refere-se ao Movimento intitulado no interior do Serviço Social de Movimento de Reconceituação ${ }^{1}$, que se pautou por uma postura contrária aos pressupostos ideológicos, teóricos e metodológicos que a

\footnotetext{
${ }^{1}$ O movimento de reconceituação significou um "processo de ruptura teórica e política com o lastro conservador de suas origens. Esse movimento do Serviço Social na América Latina teve lugar no período de 1965 a 1975, impulsionado pela intensificação das lutas que se refratavam na Universidade, nas Ciências Sociais, na Igreja, nos movimentos estudantis, dentre outras expressões" (IAMAMOTO, 2009, p. 8).
} 
profissão assumia até então. Esse movimento, que abrangeu todos os países da América Latina, culminou num evento denominado Congresso da Virada ${ }^{2}$, considerado como marco simbólico da implantação do Projeto Ético-Político.

Gradativamente, esse Projeto Ético-Político continuou se aprimorando em decorrência de novos acontecimentos importantes para a categoria profissional, tais como a instituição do Código de Ética dos assistentes sociais em 1986, que, posteriormente, em 1993, foi revisado e ampliado. Por fim, consolidou-se, a partir da década de 1990, devido ao amadurecimento dos profissionais no interior de suas organizações e ao reconhecimento dos cursos de Pós-Graduação em Serviço Social por parte das agências financiadoras de pesquisa.

Atuar em conformidade com o Projeto Ético-Político da profissão significa colocar-se numa atitude de contínua articulação entre a ética e a política, representada por um movimento de intencionalidades e ações por parte do assistente social, que se volta para uma direção social que se configura como plural e democrática. Esse movimento do pensamento e da ação, voltado à transformação, não garante a sua realização, mas se apresenta como realidade possível, como busca contínua, um embate diário, árduo e intrincado diante das incoerências, contradições e contrassensos presentes na sociedade (SARMENTO, 2011).

Para o Conselho Federal de Serviço Social (2012, p. 9), adensar as reflexões em torno da educação permanente possibilita "[...] imprimir mais avanços e consolidar uma política que valorize a qualificação profissional como um bem político, ético, técnico-operativo e um direito das/os assistentes sociais para orientar e balizar as ações do Serviço Social na direção do Projeto Ético-Político".

Portanto, a educação permanente, além de favorecer a consolidação da identidade profissional crítica e portar a tendência de se repercutir positivamente no alcance da qualidade dos serviços prestados, potencializa também as competências e as atribuições

\footnotetext{
2 Esse evento se refere "ao III Congresso Brasileiro de Assistentes Sociais (CBAS), ocorrido em setembro de 1979 em São Paulo, sendo reconhecido pela categoria profissional como Congresso da Virada, face à sua importância histórica de posicionamento dos assistentes sociais contra o conservadorismo da profissão e contra os representantes da ditadura que estavam no referido Congresso para sua abertura oficial" (RODRIGUES, 2011, p. 6).
} 
privativas dos assistentes sociais, contribuindo, assim, para a efetivação do Projeto ÉticoPolítico da profissão, conforme se pode verificar na fala do Entrevistado 4:

\begin{abstract}
Entendo o conhecimento como um meio de decifrar a realidade; auxiliar na articulação da teoria e prática, para clarificar a condução do trabalho a ser realizado. Entendo que a formação continuada é o único caminho para garantir uma atuação profissional e uma análise crítica comprometida, para que sempre se tenha como objetivo a defesa e ampliação dos direitos. A capacitação permite minha reciclagem, o que tem contribuído para ampliação do meu referencial teórico, e isso refletirá em um fazer profissional coerente e comprometido com o Projeto Ético-Político da nossa profissão (E4).
\end{abstract}

As primeiras iniciativas para a construção do Projeto Ético-Político da profissão deram-se a partir de 1970. Entre a década de 1970 e a de 1980, o Serviço Social experimentava momentos relevantes de desenvolvimento caracterizados, principalmente, pela recusa do caráter conservador do qual a profissão era imbuída. Foi em decorrência desse movimento que se fazia no interior da categoria profissional, aliado ao processo de redemocratização em que a sociedade brasileira vivia, que os fundamentos e os alicerces do Projeto Ético-Político foram construídos (NETTO, 1999).

De acordo com Raichelis (2011, p. 427-428):

\begin{abstract}
O trabalho profissional, na perspectiva do Projeto Ético-Político, exige um sujeito profissional qualificado capaz de realizar um trabalho complexo, social e coletivo, que tenha competência para propor, negociar com os empregadores privados ou públicos, defender projetos que ampliem direitos das classes subalternas, seu campo de trabalho e sua autonomia técnica, atribuições e prerrogativas profissionais.
\end{abstract}

Compreender a educação permanente para além de seus horizontes proximais permite referenciá-la como processo capaz de redesenhar os caminhos pelos quais o Serviço Social trilha na direção da efetivação de seu Projeto Ético-Político, na medida em que orienta e baliza suas ações. Nessa direção, a educação permanente se apresenta como um relevante instrumento para a qualificação das intervenções cotidianas no exercício da profissão e a capacidade de organização política da categoria (CONSELHO FEDERAL DE SERVIÇO SOCIAL, 2012).

Segundo o Conselho Federal de Serviço Social (2012), a educação permanente, aliada à formação, apresenta-se como potencial instrumento de materialização do Projeto ÉticoPolítico profissional, na medida em que a formação e a construção de conhecimentos se colocam como colunas de sustentação e consolidação desse Projeto Ético-Político. 
A Política da Educação Permanente, como conquista a ser defendida e desafio a ser arrostado coletivamente, abre as portas para a "[...] materialização do Projeto ÉticoPolítico, alargando os horizontes da intervenção profissional no conjunto das lutas sociais em direção à transformação para uma nova sociedade livre e emancipada" (CONSELHO FEDERAL DE SERVIÇO SOCIAL, 2012, p. 26).

\section{Entidades organizativas da categoria e seus contributos à consolidação da identidade profissional}

Questão de outra ordem, porém igualmente importante e complementar na consolidação da identidade profissional, é colocada com relação às entidades organizativas da categoria, que representam a dimensão político-organizativa do Serviço Social, quais sejam, o Conselho Federal de Serviço Social (CFESS), a Associação Brasileira de Ensino e Pesquisa em Serviço Social (ABEPSS) e os Conselhos Regionais de Serviço Social (CRESS).

O CEFSS encontra-se sediado em Brasília e é representado por uma autarquia situada no plano federal. Essa entidade, que funciona como tribunal superior de ética, possui, conforme Simões (2010, p. 510), “[...] personalidade jurídica própria e capacidade de representar, perante os Poderes Públicos, inclusive o Judiciário e a Sociedade Civil, os interesses coletivos e individuais dos assistentes sociais, no âmbito do exercício profissional".

A ABEPSS também é uma entidade, porém civil, de natureza acadêmico-científica, e, assim como o CEFSS, seu âmbito é nacional. Possui direito privado, sem fins lucrativos e com duração indeterminada. Foi fundada em outubro de 1946 e intitulada como Associação Brasileira de Escolas de Serviço Social (ABESS), tendo recebido a atual denominação em dezembro de 1998. Sua sede e seu foco jurídico e administrativo situamse em Brasília/DF (ASSOCIAÇÃO BRASILEIRA DE ENSINO E PESQUISA EM SERVIÇO SOCIAL, 2008).

Simões (2010) acena que o CRESS foi instituído por lei e que sua consolidação se alicerça em padrões similares ao do sistema federativo brasileiro. Esses conselhos profissionais vinculam sua competência ao exercício profissional, no âmbito do Serviço Social. A eles, enquanto entidade institucional, não cabe formular políticas de assistência social. Os CRESS representam a categoria profissional, na sua respectiva jurisdição 
administrativa, competindo-Ihes cumprir as deliberações do CEFSS, e, ainda, possuem autonomia no campo financeiro e administrativo.

De acordo com o Conselho Federal de Serviço Social (2012), a educação permanente se apresenta como uma mediadora relevante na consolidação e no aprimoramento das intervenções cotidianas realizadas pelo assistente social e na sua habilidade em gerir e administrar situações políticas. Isso atribui à educação permanente um status de potencializadora de enfrentamento político e ideológico, e é justamente por esse motivo que os órgãos representativos da categoria defendem que o cenário de formação do profissional se constitui em uma das possibilidades de fortalecimento do Projeto ÉticoPolítico.

Dessa maneira, a participação nesses órgãos representativos da categoria profissional, como no CRESS e no CFESS, contribui para a consolidação da identidade profissional, na medida em que as discussões profícuas estabelecidas nesses ambientes possibilitam e incentivam posturas críticas e ativas. A narrativa a seguir confirma essa assertiva:

Procurei sempre estar próximo ao CRESS, da seccional do Vale do Paraíba, participando em eventos, palestras, seminários, das discussões de base, sendo que em 2008, do mês de janeiro a maio, fiz parte da diretoria de transição da seccional e em 2003 eu fiz parte da Comissão de Processos Éticos, onde pude me manter sempre atualizado. Acredito que o conjunto CFESS/CRESS, apesar de alguns problemas existentes, ainda assim são canais legítimos de discussão $e$ fortalecimento da categoria. Basta a gente participar! (E1).

O Conselho Federal de Serviço Social (2012), diante da importância da qualificação continuada, acena que o CFESS e os CRESS têm se articulado para além de seus respectivos campos de atuação, interagindo também com a ABEPSS e a ENESSO, no sentido de proporcionar momentos de discussão para os profissionais, e oportunizando a inserção nos processos reflexivos contemporâneos referentes a aspectos conceituais e operativos da profissão. Segundo esse Conselho:

O conjunto CFESS-CRESS, articulado às demandas políticas e profissionais impostas à categoria, vem desenvolvendo ações de educação permanente há muitos anos, dentre as quais podemos destacar: os seminários nacionais organizados pelo CFESS para discutir a atuação profissional em campos específicos de intervenção, a exemplo de seminário sobre o trabalho de assistentes sociais na Política de Assistência Social, na Saúde, na Previdência Social, na Educação e no Campo Sócio jurídico; a realização do Congresso Brasileiro de Assistentes Sociais (CBAS), as diversas publicações que constituem 
formas de socialização das informações, debates sobre trabalho profissional, temas polêmicos e deliberações do Conjunto CFESS-CRESS, a exemplo da Revista Inscrita, dos Anais dos Encontros Nacionais CFESS-CRESS, dos Anais dos seminários nacionais realizados, a publicação de diversos CFESS Manifesta (CONSELHO FEDERAL DE SERVIÇO SOCIAL, 2012, p. 8).

Conforme defende o Conselho Federal de Serviço Social (2012), na atualidade, os Encontros Nacionais promovidos pelo CFESS e pelo CRESS têm apontado a urgência da edificação de uma Política de Educação Permanente para os profissionais de Serviço Social. Igualmente, as atenções da ENESSO se dirigem para cooperar nesse processo, compreendendo a elaboração de tal Política como uma relevante mediação para a consolidação do Projeto Ético-Político do Serviço Social.

Por outro lado, uma realidade que se faz presente e que de fato ocorre com recorrente frequência é a disponibilização de espaços de formação em locais considerados distantes pelos profissionais que atuam nas cidades do interior, afastados das grandes capitais, dos municípios de grande porte e das metrópoles, onde geralmente ocorrem esses eventos. Essa realidade dificulta a participação daqueles profissionais que não possuem tanta facilidade de locomoção como outros. Isso é verificado nas falas dos entrevistados a seguir: "Sinto muita falta da atuação do CRESS na região. Recebo convites para participar de eventos, mas a maioria, se não todos, acontecem em São Paulo [capital], o que se torna inviável ou dificulta demais a participação" (E 2).

Eu acho que os cursos de capacitação poderiam ser disponibilizados para os assistentes sociais do município com mais frequência, a gente tem muito pouco aqui no município, mas se tivesse aqui no município, se estivesse acontecendo, com certeza eu estaria conseguindo dar um jeitinho de estar participando (E3).

Não obstante as dificuldades apresentadas pelos assistentes sociais em participarem de todas as ações promovidas pelas entidades organizativas e representativas da categoria, tais impedimentos não invalidam os esforços realizados na direção da qualificação continuada por parte dessas entidades. Para Guerra (2011), a própria ABEPSS, por exemplo, com reconhecida legitimidade como entidade acadêmico-científica e política, vem investindo acentuadamente na consolidação da Pós-Graduação em Serviço Social nos últimos anos, desde sua fundação em 1946. Reconhecida por seu amparo jurídico-legal à questão da interdependência entre graduação e pós-graduação, tal associação já 
demonstra, a começar pela sua nomenclatura, o quanto se preocupa com a educação permanente do profissional.

No âmbito do Serviço Social, as entidades organizativas e representativas dos assistentes sociais, em conjunto com as unidades de formação acadêmicas, manifestam sua força de ação na direção da educação permanente. E isso ocorre por meio de discussões contínuas com a categoria profissional em torno dos referenciais teóricos, técnicos, éticos e políticos, objetivando uma intervenção profissional gradativamente mais qualificada, sintonizada com a atualidade, comprometida com a defesa dos direitos de cidadania nos diferenciados espaços sócio ocupacionais (CONSELHO FEDERAL DE SERVIÇO SOCIAL, 2012).

Essas entidades são unânimes ao expressar repetidas vezes a importância da Política de Educação Permanente, por considerarem o quanto a direção social imprimida nesse documento é capaz de se refletir positivamente no cenário da profissão. Torna-se oportuno ressaltar também que um traço bastante peculiar dessa Política consiste na possibilidade de potencialização de distintas intervenções voltadas ao processo formativo do assistente social, com a clareza de que ele não se finda na graduação, pelo contrário, efetiva-se por toda a vida (CONSELHO FEDERAL DE SERVIÇO SOCIAL, 2012).

O Conselho Federal de Serviço Social (2012), ao se pronunciar sobre a Política de Educação Permanente, reforça que ela deve referenciar a trajetória do assistente social no tempo presente e no contexto sociopolítico atual, porém, sem perder de vista a processualidade da história da profissão que se apresenta intermediada por uma variada e intricada dialética de interações sociais. Essa Política perfila direitos dos profissionais, bem como dos usuários da assistência social, ao evidenciar que se deve buscar por soluções congruentes com o compromisso pela qualidade dos serviços prestados, assim como pelo desenvolvimento das dimensões teórico-metodológica, ético-política e técnico-operativa presentes no âmbito interventivo dos assistentes sociais.

\section{Conclusões}

A NOB-RH/SUAS e a Política Nacional de Educação Permanente do conjunto CFESSCRESS configuram-se como relevantes instrumentos na democratização da importância da qualificação profissional contínua. E, apesar de saber que do ponto de vista da gestão da 
assistência social o investimento em educação permanente muitas vezes se apresenta como desnecessário, é preciso assumir uma postura de resistência em face disso. A resistência é o primeiro passo para aqueles assistentes sociais os quais reconhecem que quem cria o ambiente é quem está no cotidiano da intervenção profissional.

Assim, mais do que esperar que oportunidades de educação permanente sejam oferecidas por parte do órgão gestor, é possível realizar o movimento inverso. A parceria com as universidades e a organização profissional mobilizada em torno das entidades organizativas e representativas da categoria para a conquista de espaços é muito importante quando se trata da educação permanente, como pode-se verificar nas narrativas dos profissionais entrevistados.

No desenvolvimento e na concretização deste estudo, algumas limitações foram encontradas, sendo elas: falta de incentivo para a realização de pesquisas nos ambientes sócio ocupacionais e para o envolvimento com ações voltadas à educação permanente, levando o profissional a buscar alternativas de qualificação fora do horário de trabalho; ausência de motivação por parte dos assistentes sociais em querer participar de processos investigativos, bem como expressar seu pensamento a respeito de algumas realidades inerentes à construção e ao fortalecimento de sua identidade profissional crítica, por consequência de acúmulo de trabalho do profissional, duração de sua jornada de trabalho, entre outros motivos, gerando, por fim, outra limitação, qual seja, a dificuldade para a obtenção de respostas sobre algumas temáticas.

Acredita-se que limitações como essas representam alguns dos motivos pelos quais determinados assuntos de interesse da categoria podem, por vezes, não ser estudados pelos profissionais da forma como deveriam e, assim, contribuir para a ampliação da produção acadêmica sobre um ou outro tema específico, como, por exemplo, a educação permanente e o seu imbricamento com a consolidação da identidade profissional.

Não obstante as limitações apresentadas e reconhecidas como típicas da realidade de trabalhadores assalariados, condição na qual quase a totalidade dos assistentes sociais se encontra, esta pesquisadora assumiu um comportamento persistente na busca por respostas à inquietação emergente, por acreditar que promover um debate teórico em torno da temática educação permanente do assistente social sob o prisma da consolidação 
da identidade profissional crítica, levando em consideração as constantes transformações que se vivenciam na atualidade, é uma tarefa essencial.

Para além dos grandes desafios que se colocam diuturnamente à educação permanente, do assistente social é importante ter presente as palavras de Chiara Lubich (1987, p. 17), que encoraja a uma empreitada de tal envergadura, a qual convida a nunca cruzar os braços ao fazer a seguinte afirmação: “Não te queixes diante da luta. É a tua chance. Sem batalha, não há vitória".

\section{Referências}

ASSOCIAÇÃO BRASILEIRA DE ENSINO E PESQUISA EM SERVIÇO SOCIAL - ABEPSS. Estatuto da Associação. Brasília: UNB, 2008. Disponível em:

<http:www.abepss.org.br/documentos.php>. Acesso em: 7 fev. 2012.

BOURGUIGNON, J. A. A particularidade histórica da pesquisa no Serviço Social. Revista Katálysis, Florianópolis, v. 10, n. esp., p. 46-54, 2007.

BRASIL. Presidência da República. Constituição da República Federativa do Brasil de 1988. Brasília, 5 out. 1988. Disponível em:

<http://www.planalto.gov.br/ccivil_03/constituicao/ConstituicaoCompilado.htm>. Acesso em: 21 set. 2012.

CONSELHO FEDERAL DE SERVIÇO SOCIAL - CFESS. Política de Educação Permanente do Conjunto CFESS-CRESS. Brasília, 2012. Disponível em: <www.cfess.org.br $>$. Acesso em: 20 set. 2012.

FREIRE, P. Pedagogia do oprimido. 23. ed. Rio de Janeiro: Paz e Terra, 1994.

GATTI, B. A.; BARRETO, E. S. S. (Coord.). Professores do Brasil: impasses e desafios. Brasília: UNESCO, 2009.

GUERRA, Y. A Pós-Graduação em Serviço Social: um patrimônio a ser preservado. Temporalis, Brasília, v. 2, n. 22, p. 125-158, jul./dez. 2011.

IAMAMOTO, M. V. O Serviço Social na cena contemporânea. 2009. Disponível em: <http://www.prof.joaodantas.nom.br/materialdidatico/material/1__O_Servico_Social_na_cena_contemporanea.pdf>. Acesso em: 8 abr. 2012. Serviço social em tempo de capital Fetiche. 5. ed. São Paulo: Cortez, 2011.

LUBICH, C. 99 Pensamentos escolhidos. São Paulo: Cidade Nova, 1987.

MARTINELLI, M. L. Serviço Social: identidade e alienação. 16. ed. São Paulo: Cortez, 2011. MINAYO, M. C. S. Introdução. In: ; ASSIS, S. G.; SOUZA, E. R. (Org.). Avaliação por triangulação de métodos: abordagem de programas sociais. Rio de Janeiro: Fiocruz, 2010. 
NETTO, J. P. A construção do projeto ético-político do serviço social. In:

Capacitação em Serviço Social e Política Social. Brasília: Cead/ABEPSS/CFESS, 1999.

Modulo 1. Disponível em: <http://www.fnepas.org.br/pdf/servico_social_saude/texto2-

1.pdf>. Acesso em: 9 abr. 2012.

RAICHELIS, R. O assistente social como trabalhador assalariado: desafios frente às

violações de seus direitos. Serviço Social \& Sociedade, São Paulo, v. 32, n. 107, p. 420-437, jul./set. 2011.

RODRIGUES, A. T. S. As expressões do projeto ético-político do serviço social no exercício profissional do assistente social no Conselho Municipal da Assistência Social. 2011. 56f. Trabalho de Conclusão de Curso (Graduação em Serviço Social) - Faculdade de Serviço Social, Universidade de Taubaté, Taubaté, 2011.

SARMENTO, H. B. M. Ética e serviço social: fundamentos e contradições. Revista Katálysis, Florianópolis, v. 14, n. 2, p. 210-221, jul./dez. 2011.

SEVERINO, A. J. Prefácio. In: MARTINELLI, M. L. Serviço social: identidade e alienação. São Paulo: Cortez, 2011.

SIMÕES, C. Curso de Direito do serviço social. 4. ed. São Paulo: Cortez, 2010.

SPOSATI, A. Pesquisa e produção de conhecimento no campo do Serviço Social. Revista Katálysis, Florianópolis, v. 10, n. esp., p. 15-25, 2007. 